\title{
Aude Le Roux-Kieken, Imaginaire et écriture de la mort dans l'œuvre de Marcel Proust
}

\section{Emanuele Kanceff}

\section{(2) OpenEdition}

1 Journals

\section{Edizione digitale}

URL: http://journals.openedition.org/studifrancesi/33583

DOI: 10.4000/studifrancesi.33583

ISSN: 2421-5856

\section{Editore}

Rosenberg \& Sellier

\section{Edizione cartacea}

Data di pubblicazione: 1 décembre 2005

Paginazione: 673

ISSN: 0039-2944

\section{Notizia bibliografica digitale}

Emanuele Kanceff, «Aude Le Roux-Kieken, Imaginaire et écriture de la mort dans l'œuvre de Marcel Proust», Studi Francesi [Online], 147 (XLX | III) | 2005, online dal 30 novembre 2015, consultato il 18 avril 2021. URL: http://journals.openedition.org/studifrancesi/33583 ; DOI: https://doi.org/10.4000/ studifrancesi.33583

Questo documento è stato generato automaticamente il 18 avril 2021.

\section{(c) (1)}

Studi Francesi è distribuita con Licenza Creative Commons Attribuzione - Non commerciale - Non opere derivate 4.0 Internazionale. 


\title{
Aude Le Roux-Kieken, Imaginaire et écriture de la mort dans l'œuvre de Marcel Proust
}

\author{
Emanuele Kanceff
}

\section{NOTIZIA}

AUDE LE ROUX-KIEKEN, Imaginaire et écriture de la mort dans l'œeuvre de Marcel Proust, Paris, Honoré Champion Éditeur, 2005 («Recherches proustiennes», 7), pp. 496.

1 Morte, sonno, vecchiaia sono strettamente legati per Proust. Tenendo conto degli studi già pubblicati sull'argomento o attinenti, che sono elencati nella bibliografia finale, l'A. intende offrire un'interpretazione dell'insieme di immagini sulla morte che si possono reperire nelle opere di Proust anche non narrative, incominciando da un esame delle diverse influenze che gli stereotipi derivanti dalla "saggezza popolare" possono aver esercitato sulla scrittura proustiana della morte, per seguitare con i "topoi" mitologici, apocalittici e cristiani, le considerazioni romantiche sulle rovine e la loro valenza simbolica. Tutto ciò nel tentativo primario di determinare come l'immagine proustiana s'insinui o si discosti dallo stereotipo. Il secondo capitolo dello studio cerca una definizione della morte conforme alla concezione proustiana, differenziando il punto di vista dell'autore da quello del narratore e tenendo conto delle tensioni del discorso sulla morte in riferimento alle condizioni di produzione. Successivamente, l'A. cerca di mostrare che la maggioranza delle immagini della morte nascono dall'intima convinzione di una morte positiva e di una morte frammentaria, mettendosi in cerca delle coincidenze tra l'espressione di un insieme di passaggi sulla morte e la costellazione di immagini che danno consistenza a questa entità non conoscibile nel romanzo e identificando nella scelta delle immagini l'espressione quasi incosciente delle convinzioni proustiane esplicitate nel discorso. A questo punto non resta che 
entrare nello studio analitico dell'immaginario della morte, che appartiene a tre grandi regni, il vegetale, l'animale e il minerale, rflettendo in parallelo sull'arte che ne emerge.

2 Attraverso i regni così come attraverso gli stili, le epoche, gli anni, si disegnano per l'A. dei grandi archetipi immaginari della morte, che sono anche dei diversi modi di rapportarsi alla condizione umana, all'amore, all'eredità, al sonno, alla religione, all'arte, all'immortalità, e gli elementi che offrono un testo romanzesco di grande complessità e bellezza. 